\title{
Atendimento às Mulheres em Situação de Violência no Centro de Referência Francisca Trindade, em Teresina - PI
}

\author{
Care Situation of Women under Violence in the Center of Reference Francisca \\ Trinity in Teresina - PI
}

\author{
Mayara Alves Lima Lira \\ Univesidade Federal do Piauí \\ maylinda.cs@gmail.com
}

\section{Resumo}

Esta pesquisa teve como objetivo analisar o atendimento as mulheres em situação de violência no Centro de Referência Francisca Trindade, situado na zona norte de Teresina-Pi. Os Centros de Referência são estruturas essenciais da política de prevenção e enfrentamento à violência contra a mulher. No entanto, atendimentos inadequados podem corroborar a continuidade da violência. Utilizou-se uma metodologia de cunho qualitativo, através da técnica de observações sistemáticas do atendimento profissional no Centro de Referência. Consideraram-se como indicadores do atendimento adequado as condições estruturais e o atendimento especializado e integrado em rede. Os resultados, em geral, revelam um atendimento não adequado, tanto no que se refere às condições estruturais, como ao atendimento especializado em si.

Palavras-chave: Gênero: Violência; Atendimento; Centro de Referência.

\begin{abstract}
This research aimed to analyze the care of women in situations of violence in the reference center Francisca Trindade, situated in the North of the city of Teresina, state of Piauí, Brazil. The reference centers are essential structures in the policy for preventing and defeating violence against women. However, an inadequate care can corroborate the continuity of violence. We used a qualitative methodology, through a technique of systematic observation of the professional service done in the reference center. It were considered as indicators of an adequate care the structural conditions of the center and the presence of specialized care and integrated networking. The results generally show a service that is not suitable with regard both to the structural conditions and to the specialized service itself.
\end{abstract}

Keywords: Gender: Violence; Service; Reference Center. 


\section{Introdução}

A visibilidade e poder da mulher na sociedade contemporânea vêm aumentando gradativamente através dos séculos, essa passou, cada vez mais a adentrar em espaços pertencentes ao público masculino. Foram muitas as conquistas, passaram a ter voz ativa na política, livre acesso ao seu corpo e sexualidade, crescente participação no mercado de trabalho e maior acesso a educação. Mas apesar dos progressos, ainda se presencia a perseverança das desigualdades e hierarquias de gênero entre homens $\mathrm{e}$ mulheres nas esferas públicas e privadas, consequências do patriarcalismo e machismo presentes, ainda, em nossa sociedade, um exemplo concreto é a violência de gênero, particularmente a violência conjugal.

A violência contra a mulher é caracterizada como uma violência de gênero (ALVES \& DINIZ, 2005). É um problema social e de saúde pública que independe de etnia, credo, condição financeira ou idade, afetando vários grupos sociais, o que torna sua visualização, prevenção e combate mais complexos, já que se tem de enfrentar tal problemática por várias frentes.

As reivindicações do movimento feminista vêm lutando pelo direito das mulheres desde o século XIX, nos anos oitenta essas reivindicações se intensificaram no Brasil, levando a mudanças sobre a violência contra mulher, que passou a ser vista não só como um problema social, mas como um crime, e não mais como um assunto particular do casal. Essas mudanças proporcionaram a aplicação de medidas intervencionistas por parte da sociedade civil, dentre essas medidas encontram-se a criação dos serviços especializados de atendimento a mulher que enfrentam uma situação de violência conjugal.

A criação de mecanismos de caráter institucional para conscientizar, combater e prevenir a violência de gênero foram fundamentais para a mudança desse quadro de violência, tendo em vista que o rompimento de uma situação de violência conjugal necessita de uma intervenção externa. Dentre estes mecanismos estão os Centros de Referência, eles foram criados na década de noventa tendo como modelo o SOS mulher ${ }^{1}$, surgiram como um aparelhamento estratégico na rede antiviolência, dando auxílio aquelas mulheres que precisavam de atendimento psicológico, orientação social e jurídica (SILVEIRA, 2005). O trabalho dos Centros tem, uma função de caráter conscientizador e assistencial complementando o trabalho de outras instituições da rede de atendimento como as Delegacias Especializadas de Atendimento à Mulher e as Casas Abrigo.

Os Centros de Referência e, consequentemente, seus funcionários devem compor um núcleo de assistência multiprofissional na rede de atendimento a mulheres. Seu trabalho tem como meta intervir no ciclo da violência, se utilizando da escuta integral dessa violência de forma unificada. A escuta é realizada através do trabalho de uma equipe multidisciplinar constituída de assistentes sociais, advogados, psicólogos, pedagogos e terapeutas ocupacionais (SILVEIRA, 2005).

As mulheres que sofrem violência ao procurarem ajuda nas instituições especializadas se encontram muito fragilizadas e por isso demonstram dificuldades para expor seus problemas a pessoas estranhas. Nesse sentido, quando as usuárias se deparam com condições adequadas de escuta e acolhimento, essas tendem a revelar mais violências sofridas em seu cotidiano. Quando ocorre o contrário, as mulheres encontram atitudes preconceituosas e desqualificadoras por parte dos profissionais, essas permanecem em silêncio ou dizem estritamente o necessário (NORA, STREY \& WERBA, 2004). Dessa forma, a capacitação dos profissionais na área de gênero, as condições estruturais e a integração dos Centros de Referência à rede antiviolência são elementos que podem influenciar na qualidade e eficácia do serviço prestado por essas instituições.

Diante do exposto, fica justificada a necessidade de se verificar as condições estruturais e profissionais em que ocorre o atendimento no Centro de Referência para Mulheres, procurando constatar se este atende de forma adequada às diretrizes de funcionamento da Norma Técnica de Uniformização dos Centros de Referência (2006). Considerando que o atendimento e acolhimento a essas mulheres se constituem em momentos relevantes para conscientização e ação reflexiva das mesmas sobre a violência sofrida (NORA, STREY \& WERBA, 2004).

Nesse sentido, a presente pesquisa teve como objetivo analisar o atendimento profissional no Centro de Referência para Mulheres Vítimas de Violência Francisca Trindade, em Teresina, a fim de verificar as condições estruturais, a qualificação profissional na área de gênero e a integração à rede de atendimento às mulheres em situações de violência doméstica na cidade.

Através de observações realizadas sobre o atendimento e conversas informais com funcionários se pode constatar que esta instituição não atende a muitas das diretrizes da Norma Técnica de Uniformização, no que se refere aos recursos humanos, segurança, localização e integração à rede de atendimento a mulher.

Os serviços oferecidos pelos Centros de Referência às mulheres em situação de violência devem 
possibilitá-las a recuperar a história de violência que enfrentaram podendo, assim, refletir sobre a mesma, o que as leva a tomarem uma posição e saírem do papel passivo de vítima. O que lhes dá a possibilidade de reagir. Portanto, os Centros de Referência têm um papel tão importante quanto o das DEAMS no combate a violência de gênero, tendo em vista que tais instituições auxiliam na continuidade do atendimento as mulheres que utilizam os serviços da DEAM, primeiro contato das mulheres com o Estado para resolução do problema.

\section{Fundamentação Teórica}

A violência doméstica e intrafamiliar tornaram-se evidentes como um grave problema social pelos efeitos intensos que tem na saúde física e mental das mulheres, comprometendo sua qualidade de vida. Caracterizada como uma violência de gênero é um problema de direitos humanos e saúde pública que ocorre, geralmente, num contexto de relação afetiva e predominante no interior dos domicílios sendo, na maioria das vezes, praticada por seus cônjuges ou companheiros (SAFFIOTI, 1999; VELÁZQUEZ, 2006). Segundo a lei 11.340 de 2006, tal violência "se configura como qualquer ação ou omissão baseada no gênero que cause morte, lesão, sofrimento físico, sexual ou psicológico e dano moral ou patrimonial a mulher". Dessa forma, a categoria de gênero se torna necessário, para a compreensão das relações entre os sexos em um contexto de violência.

O gênero é um elemento constitutivo das relações sociais baseado nas diferenças percebidas entre os sexos e a primeira forma de significar as relações de poder (SCOTT, 1989). Tratam da construção social dos papéis desempenhados por homens e mulheres na sociedade. Tem caráter relacional, ou seja, o entendimento de um implica, consequentemente, no entendimento do outro. Em outros termos pode ser interpretado como um conjunto de normas modeladoras dos seres humanos aplicadas a homens e mulheres, sendo expressas nas relações sociais públicas e privadas dessas categorias (SAFFIOTI, 1999).

Tradicionalmente, costuma-se atribuir às mulheres um comportamento frágil, dependente, submisso e aos homens atitudes dominadoras e agressivas, o que acaba levando ao estabelecimento de hierarquias e desigualdades entre os sexos. Essas desigualdades não são naturais, são impostas pela tradição cultural, estruturas de poder e agentes envolvidos na organização das relações sociais. Tal desigualdade de gênero não é colocada previamente, mas pode ser construída e o é com frequência. As instituições sociais como família, escola e igreja, de certa forma, legitimam tais atitudes, o que colabora para a ininterrupção da violência conjugal, que continua a ser considerada como uma prática natural em relacionamentos amorosos (ALVES \& DINIZ, 2005; BOURDIEU, 2002; SAFFIOTI, 1999).

A violência doméstica é uma prática naturalizada em nossa sociedade, por tal motivo as mulheres têm dificuldade de se colocarem no papel de vítimas e de reconhecerem seus parceiros como agressores, existindo também uma ideologia de defesa da família, medo das ameaças, receio de criarem os filhos sozinhas, dependência financeira e fragilidade emocional que faz com que se submetam a violência e não a denuncie (SAFFIOTI, 1999; SILVEIRA, 2005; STREY, NORA \& WERBA, 2004).

Nesse sentido, a criação de políticas públicas que objetivem combater e prevenir o ciclo da violência conjugal é imprescindível e, dessa forma para enfrentá-la, um grupo de trabalho especializado deve problematizar questões sociais e culturais que estão embutidas na constituição das identidades, estereótipos e relações de poder entre os gêneros (VELÁQUEZ, 2006).

Nessa perspectiva, a formulação das redes de enfrentamento e atendimento às mulheres em situação de violência foi um marco importante. As redes de enfrentamento e atendimento são componentes do pacto nacional de enfrentamento a violência contra mulher. Esse pacto é uma iniciativa do governo e tem como objetivo geral combater todas as formas de violência contra as mulheres por meio de uma visão integral do fenômeno. Consiste no desenvolvimento de políticas públicas amplas e articuladas direcionadas, prioritariamente, às mulheres rurais, negras e indígenas em situação de violência, em função da dupla ou tripla discriminação que sofrem em virtude da maior vulnerabilidade social a que estão submetidas (PACTO NACIONAL, 2007).

Ambas as redes atuam no combate a violência, mas seus eixos de atuação diferem, pois a rede de enfrentamento aborda todos os eixos da política nacional de enfrentamento da violência, incluindo os órgãos responsáveis pelo controle social e gestão de políticas de gênero e serviços de atendimento, apresentando-se de forma mais ampla que a rede de atendimento. Enquanto a rede de atendimento tem como foco o assistencialismo, restringindo-se aos serviços de atendimento especializados e não especializados, se apresentando como um componente da rede de enfrentamento (REDE DE ENFRENTAMENTO, 2010).

A rede de enfrentamento a violência contra as mulheres trata da articulação e integração de serviços 
governamentais, Ong's e comunidade, objetivando a construção de estrategias efetivas de prevenção da violência, políticas que possibilitem as mulheres o acesso dos seus direitos, a responsabilização dos agressores e assistencialismo adequado. Tal rede é consequência das reivindicações feministas, sendo composta por instituições como os Centros de Referencia, as Casas Abrigo, Postos de Saúde e Hospitais, Instituto Médico Legal-IML, Serviços Jurídicos, Delegacias Especializadas. A articulação entre esses serviços possibilita a formação de um fluxo de atendimento que visa garantir a qualidade dos serviços prestados (NORMA TÉCNICA, 2010; REDE DE ENFRENTAMENTO A VIOLÊNCIA, 2010).

A rede de atendimento também se refere à atuação conjunta de instituições governamentais, Ong's e comunidade, mas tem como foco a ampliação e melhoria da qualidade dos serviços especializados da rede. A construção da rede tem como meta abarcar a complexidade da violência de gênero de forma multidimensional, passando pelas áreas de saúde, educação, segurança pública, justiça, assistência social e cultura. Tendo em sua constituição serviços especializados que atuam como porta de entrada para futuros encaminhamentos das mulheres atendidas, trabalhando de forma intersetorial.

A ação dos Centros de Referência na rede de atendimento é fundamental, já que é nesses espaços que se presta acolhimento, orientação e acompanhamento às mulheres em situação de violência ajudando-as a superar o ocorrido. Visam promover a ruptura da situação de violência e a construção da cidadania por meio de ações globais e de atendimento interdisciplinar à mulher, exercendo o papel de articuladores dos serviços dos organismos governamentais e não governamentais que integram a Rede (NORMA TÉCNICA DE UNIFORMIZAÇÃO, 2006).

$\mathrm{O}$ atendimento oferecido deve pautar-se no acolhimento permanente às usuárias, monitorando e acompanhando ações desenvolvidas por instituições que compõem a rede e instituindo procedimentos de referência. Os profissionais devem embasar suas práticas no questionamento das relações de dominação e opressão entre os gêneros. Ressaltando-se que o foco da intervenção está na prevenção de futuras agressões e término do ciclo de violência (ARAUJO \& MELO, 2009; NORMA TÉCNICA DE UNIFORMIZAÇÃO, 2006).

Em março de 1990 foi criada a 'Casa Eliane de Grammont'2, localizada na cidade de São Paulo, o primeiro Centro de Referência a mulher no país. Em 1996, na cidade de Belo Horizonte, foi criado o 'Benvinda'. Durante a década de noventa o combate a violência contra mulher estava fundamentado no binômio delegacia/casa abrigo, por isso não havia visibilidade e reconhecimento dos Centros de Referência apesar destas instituições apresentarem um caráter preventivo e integral.

Segundo Côrtez (2008) houve um aumento quantitativo expressivo na inserção dos Centros de Referência, em 2002 existiam somente 17 em todo país, em 2006 chegou a 83 instituições e, em 2008 havia um total de 99 instituições. De acordo com dados da Secretária de Políticas Públicas para Mulheres, desde a promulgação da Lei Maria da Penha, em 2006, ocorreu uma multiplicação de serviços especializados de atendimento a mulher, no que se refere aos Centros de Referência. Atualmente o Brasil apresenta 202 instituições distribuídas da seguinte maneira, 17 no norte, 49 no nordeste, 75 no sudeste, 32 no sul e 29 no centro-oeste.

De acordo com Silveira (2005), o público atendido é bem particular, são mulheres que buscam uma forma de terminar o relacionamento violento sem a intervenção policial, assim os Centros apresentam-se como uma alternativa para a resolução do conflito violento. Nessa perspectiva, a intervenção junto às usuárias privilegia a ideia de reconduzir a mulher a um lugar de autonomia, retirando-a do lugar passivo de vítima (MORAES \& GOMES, 2009).

A rede de atendimento à mulher em situação de violência no Piauí se estabelece através de uma parceria entre a Secretária de Políticas Públicas para as Mulheres e o governo do Estado por meio da Diretoria da Unidade de Políticas para Mulheres. Essa Secretaria é composta por instituições como Delegacias Especializadas de Atendimento à Mulher (DEAM), Núcleo de Defesa da Mulher na Defensoria Pública, Casa Abrigo, Serviço de Atenção à Mulher Vítima de Violência Sexual (SANNVIS), Diretoria da Unidade de Políticas para Mulheres (DUPM), Juizados de Violência Doméstica e Familiar contra a mulher, Varas adaptativas de violência doméstica e familiar.

No Estado do Piauí só existe o Centro de Referência para Mulheres Vítimas de Violência Francisca Trindade, localizado na zona norte da cidade de Teresina, inaugurado em 2007. O mesmo é gerenciado pela Secretaria de Assistência Social e cidadania- SASC do município. O Centro tem o atendimento voltado à mulher vítima de violência, funcionando de forma integrada à Rede de Atendimento à Mulher, juntamente com o Instituto médico Legal (IML), Delegacias Especializadas de Atendimento a Mulher (DEAM), Casa Abrigo e Defensória Pública.

$\mathrm{O}$ atendimento prestado tem como meta complementar o trabalho das outras instituições da 
rede de atendimento no Estado, intensificando o atendimento psicológico, social e jurídico de forma individual ou em grupos, visando o bem estar e pleno exercício da cidadania feminina. Para alcançar tal meta a instituição, no período de 2007 a 2009, se utilizava do encaminhamento das usuárias aos diversos serviços da rede, visitas domiciliares, mediação de conflitos, realização de grupos de convivência ${ }^{3}$, oficinas e cursos de capacitação. Também são desenvolvidos projetos, campanhas e ações que orientam e informam as mulheres sobre seus direitos, além de conscientizar e sensibilizar a comunidade sobre a violência de gênero (ARAUJO \& MELO, 2009).

A qualidade do atendimento prestado, em geral pelos Centros de Referência tem grande relevância no enfrentamento e combate da violência contra a mulher. Um bom atendimento se caracteriza pela escuta e acolhimento adequados às usuárias, que precisam sentir-se seguras para falar de seus problemas e, assim, poder enfrentá-los. Precisam sentir que serão respeitadas e tratadas com dignidade por aqueles que irão lhes atender, escutar e ajudar. Os profissionais, por sua vez, devem proporcionar uma escuta refinada e sensível para ouvir ao que as mulheres têm a dizer sobre a violência sofrida (VELÁZQUEZ, 2006; STREY, NORA \& WERBA, 2004).

Por meios dos serviços oferecidos as mulheres têm a possibilidade de recuperar a história de violência que enfrentaram podendo, assim, refletir sobre a mesma, o que as leva a tomarem uma posição, saírem do papel passivo de vítima e reagir. A principal meta do atendimento é auxiliar a superação da relação violenta, o que não significa necessariamente a separação conjugal. Portanto, os Centros possuem um papel importante no combate à violência contra a mulher.

\section{Metodologia}

Tendo como objetivo analisar o atendimento profissional às mulheres em situação de violência, no Centro de Referência para mulheres vítimas de violência Francisca Trindade, na cidade de Teresina, utilizou-se a abordagem qualitativa, tendo em vista que esta abordagem permite uma apreensão mais detalhada dos significados presentes nas práticas e discursos dos profissionais no referido lócus de investigação (GOLDEMBERG, 2007).

A escolha do Centro de Referência como lócus deste estudo, se deu a partir da minha participação na pesquisa: 'Violência contra a mulher em Teresina: analisando $\mathrm{o}$ atendimento nas delegacias especializadas', que ocorreu no período de 2009 a 2011, coordenada pela Professora Mary Alves Mendes, na qual se teve a oportunidade de ir a esse Centro de
Referência para saber informações sobre o encaminhamento das mulheres pela DEAM a esse Centro. Intrigou-me o fato do Centro estar localizado no mesmo espaço geográfico que a DEAM e mesmo assim nem todas as mulheres atendidas tinham conhecimento dos serviços desta instituição.

Os instrumentos ou técnicas de coleta escolhidas para a apreensão das informações de campo foi à observação sistemática ${ }^{4}$ feita junto aos funcionários no seu ambiente de trabalho. A observação participante permitiu a essa pesquisadora aproximar-se dos sujeitos da pesquisa tornando-se parte do ambiente dos mesmos podendo assim compreender as ações praticadas por tais sujeitos (MAY, 2004).

Optou-se metodologicamente por utilizar a 'observação sistemática' sobre o local, atendimento e funcionamento do Centro e trabalho desses profissionais, além das informações advindas das 'conversais informais' e diárias mantidas com os mesmos, que tinham conhecimento do propósito dessa pesquisadora no estabelecimento, assim como do registro das informações obtidas em Diário de Campo.

Os procedimentos metodológicos aplicados para efetivar esse processo de pesquisa iniciaram com um levantamento bibliográfico sobre a temática em discussão, tendo como base leituras sobre gênero, violência de gênero, rede atendimento a violência doméstica, particularizando os Centros de Referência, lócus de investigação dessa pesquisa. Percorrer as etapas desse processo metodológico teve por objetivo aprofundar o conhecimento bibliográfico sobre a temática investigada e ter melhor domínio dos significados presentes nos discursos dos sujeitos objetos da pesquisa (funcionários do Centro de Referência).

A partir de um roteiro semiestruturado, elaborado durante a construção do projeto de pesquisa e com a devida autorização da Diretoria da Unidade de Políticas para Mulheres- DUPM, ${ }^{5}$ deu-se início a pesquisa de campo, efetivada no período de 20/10/11 a 07/11/11, no horário das 8:00h as $12: 00 \mathrm{~h}$, junto ao Centro de Referência Francisca Trindade. As observações feitas se ativeram aos espaços de atendimento no Centro (a recepção, sala de atendimento jurídico, sala de atendimento psicológico e social) procurando observar os aspectos prédefinidos no roteiro. Após o término das observações realizou-se a organização, categorização e transformação das informações coletadas em dados etnográficos de pesquisa nos aspectos predefinidos anteriormente. 


\section{Atendimento no Centro de Referência para Mulheres Vítimas de Violência Francisca Trindade}

Através de observações sistemáticas do atendimento e conversas informais com os profissionais do Centro de Referência para Mulheres Vítimas de Violência Francisca Trindade, foram coletadas informações que demonstram as atuais condições em que se encontra o funcionamento e atendimento nessa instituição.

Os aspectos selecionados para a observação e análise do atendimento estavam relacionados as 'condições físico-estruturais do local', particularmente no que diz respeito à acessibilidade e a adequação das instalações físicas ao público, a logística necessária para a execução dos serviços diários, a articulação e integração do Centro com as demais instituições da rede de atendimento, funcionários suficientes para atendimento e procedimentos profissionais qualificados (escutas, acolhimento, orientações, encaminhamentos e acompanhamentos continuados dos casos atendidos), tendo em vista que tais aspectos influenciam na qualidade e eficácia dos serviços prestados.

Esse Centro de Referência se localiza no bairro Buenos Aires, na mesma área geográfica que abriga a Delegacia de Atendimento Especializado a MulherDEAM norte, o Centro Social Urbano- CSU e o Juizado de Pequenas Causas. Mesmo com essas instituições que poderiam ser pontos de referência para as usuárias que procuram o Centro, existem dificuldades para a sua acessibilidade e visibilidade, pois não há placas de indicação e a pintura da faixada do prédio está bem desgastada. $\mathrm{O}$ acesso das usuárias ocorre, na maioria das vezes, por meio de indicações e encaminhamentos da referida DEAM.

O C.R funciona de segunda a sexta-feira no horário das 7:30h as 13:00h, expediente corrido. A equipe é composta por oito funcionários (1 recepcionista, 2 auxiliares de serviço geral, 3 vigilantes, 1 assistente social e 1 coordenadora). A estrutura física apresenta sete repartições, aonde acontece a recepção, atendimento psicológico, jurídico e social, coordenação, além de dois banheiros, um para uso dos funcionários e outro para uso do público, um almoxarifado que funciona como depósito e cantina, um auditório e um carro utilitário.

De forma geral, as estruturas físicas do prédio demonstram problemas como infiltração, rachaduras no teto e nas paredes, cupins, instalações elétricas velhas e deterioradas. Observou-se que os funcionários se sentem incomodados com a situação do prédio e o consideram inadequado, como pode ser visto na fala dessas funcionárias ao dizerem que "a estrutura não favorece e nem é prazerosa" (C.R 25/11/11, 9:50h), "a estrutura é precária, não é confortável" (C.R 25/11/11 $10: 15 \mathrm{~h})$.

$\mathrm{O}$ auditório se encontra desativado no momento e tem sido alvo de depredações de vândalos e usuários de drogas que estão utilizando o local para consumo e roubo de todo e qualquer material que possua algum valor. Essa situação que se iniciou no começo do ano, vem se arrastando e piorando a situação de funcionamento e segurança do Centro em geral. O local está muito deteriorado como pode ser visto no seguinte comentário: "O auditório está parecendo a cracolândia. Tem palito no chão, fezes, resto de pedra de craque" (C.R 27/10 9:40h).

A ausência de segurança no local, para as usuárias e funcionários, é um problema grave e vem prejudicando o atendimento de forma adequada no Centro, como exige as Normas de Padronização em relação às instituições que formam a rede de atendimento. No período da inauguração, em 2007, a instituição contava com dois policiais militares responsáveis pela segurança, mas atualmente só conta com três vigilantes que não possuem capacitação para esse tipo de atuação. Tal situação atrai e tem aumentado a ação de vândalos ao ponto das portas serem fechadas no horário de atendimento.

No dia 28/10/11 ao chegar à instituição constatouse que havia faltado energia e o problema ocorreu devido a um furto de fios, como revela uma funcionária: "os vândalos roubaram toda a fiação da caixa de energia" (C.R 28/10/11, 9:30h). As instalações elétricas já estão velhas e por isso o eletricista encontrou dificuldades para resolver os problemas. Por causa desse ocorrido o Centro de Referência ficou sem funcionar durante três dias, reiniciando o atendimento somente no dia 03/11.

Em razão da precariedade e problemas das estruturas funcionais do prédio, foi solicitada pela coordenadora a transferência urgente do referido Centro para o prédio da Ouvidoria do Estado, aonde funciona a Diretoria de Políticas para Mulheres, e a Diretoria dos Direitos Humanos. Conforme informações das funcionárias, tal transferência deve ocorrer até o final deste ano. Os funcionários aceitaram bem a transferência, acreditam que esta seja a melhor solução no momento, apesar de ter algumas dificuldades de acessibilidade para portadores de necessidades especiais "o espaço é enorme, melhor do que aqui. Só tem um problema, não tem acessibilidade, só tem escadas" (C.R 03/11/11 11:21h); "é melhor mesmo, aqui a gente tá correndo perigo, pela falta de segurança e por conta do prédio" (C.R 03/11/11 11:30h). 
De forma geral, pode-se averiguar que às condições físico-estruturais não atendem as especificações presentes nas Normas Técnicas de Uniformização (2006). O Centro deveria estar localizado em um local bem iluminado, com placas de indicação que facilitassem o acesso da população. Apesar de estar bem próximo a outro órgão da rede de atendimento, DEAM, não se observou comunicação assídua e nem trabalho integrado entre as instituições.

A Norma Técnica (2006) sugere que a segurança dos profissionais e das mulheres em situação de violência deve ser preservada em todos os procedimentos de atendimento, o que não parece acontecer nessa instituição. Observou-se que no período de uma semana o Centro passou por outros roubos (portas, motor de uma geladeira) que não tiveram resolução, apesar da Delegacia Especializada se encontrar a menos de duzentos metros e existir um Posto da Polícia Militar no bairro.

No que diz respeito ao atendimento às mulheres vítimas de violência física, sexual e psicológica ocorre de forma sequencial. Dentre as atividades desenvolvidas pelo encontra-se: o atendimento por agendamento, que consiste no acesso das usuárias à instituição através de horário marcado para atendimento; a escuta individual e específica das mulheres, de acordo com a demanda dessas à assistência social, atendimento jurídico ou psicológico; atendimentos por encaminhamento, que se trata do direcionamento das mulheres à rede antiviolência, ou seja, a usuária chega geralmente encaminhada pela DEAM e durante o atendimento é verificado qual a sua necessidade (assistência jurídica ou tratamento psicológico), em seguida é feito o encaminhamento dessa mulher a outra instituição da rede que preste o serviço específico, como o núcleo de defesa da mulher.

A visita domiciliar, à casa das mulheres, é outro procedimento de trabalho. Tais visitas ocorrem quando necessitam de um acompanhamento (nas situações em que a mulher sofre agressão e continua na mesma casa que o agressor, está precisando de um acompanhamento psicológico, mas não pode se deslocar até centro).

Há ainda grupos de convivência, espaços destinados a troca de experiências entre as mulheres que se encontram em situação de violência, como também oficinas e cursos de capacitação (corte e costura, bijuterias, manicure dentre outros) que consiste na oferta de conhecimentos e atividades práticas que viabilizem certa independência financeira das usuárias.

O desenvolvimento dessas atividades é realizado pela equipe técnica composta por três profissionais: assistente social, psicóloga e advogada. Cada uma tem uma função específica a assistente social é responsável pela execução de programas e projetos de assistência social, visitas em domicílio e realização de atividades de caráter educativo; a psicóloga é encarregada pelo atendimento psicológico aplicando técnicas terapêuticas que favoreçam ao desenvolvimento social e emocional, promovendo a sua autoestima; a advogada presta o atendimento jurídico, orientando acerca dos seus direitos, fazendo encaminhamentos e acompanhamentos aos serviços de atendimento jurídico (audiências na defensoria e DEAM).

No momento, a equipe está reduzida estando ausentes, desde o final de 2010, profissionais da área jurídica e da psicologia. A advogada que atuava no Centro, desde sua fundação, era terceirizada e devido a uma liminar da justiça para que profissionais concursados assumissem cargos públicos disponíveis foi afastada, já a psicóloga era funcionária efetiva, mas estava passando por problemas pessoais e por isso pediu uma licença sem vencimento no início deste ano. Segundo comentários das funcionárias, foram feitas várias solicitações a Secretaria de Assistência Social e Cidadania- SASC, mas até o momento e finalização da etapa dessa pesquisa de campo, essas ainda não tinham sido atendidas. "No momento nossa equipe encontrase bem desfalcada, e não é por falta de pedidos" (C.R 07/11/11 11:05h).

Por esse motivo, o atendimento do C.R ficou praticamente reduzido à recepção, aonde a usuária faz uma ficha contendo apenas dados pessoais, mas não relata a violência nesse momento, e sabe-se que o pilar do atendimento seria a reduzir a sua exposição, visto que está muito fragilizada. "a gente recebe, se ela começa a relatar a violência, a gente pondera e fala que ela vai ser encaminhada a pessoa capacitada" (C.R 27/11/11 10:30h). Na sequência, a usuária é encaminhada a assistente social que faz uma triagem ${ }^{6} \mathrm{e}$ inicia os devidos encaminhamentos para demais instituições da rede. Sobre como atender as mulheres em situação de violência, uma funcionária se coloca da seguinte forma: "atender bem é acolher. Se a mulher estiver nervosa, dou uma água ou água com açúcar, até ela se acalmar e poder prosseguir com o atendimento" (C.R 26/11/11 11:00h).

Conforme o comentário de outra funcionária o atendimento oferecido pelo Centro de Referência busca uma intervenção na situação de violência não se baseia só no assistencialismo, procurando dar a mulher formas de sair do ciclo da violência: "não utilizamos o assistencialismo, buscamos tirar a mulher da situação de violência, tentando superar a dependência financeira" (C.R 07/11/11 11:00h). Para cumprir tal meta a coordenadora dessa instituição tem a função de articular e propor ações entre órgãos ligados a 
Secretaria de Assistência Social e Cidadania- SASC, procurando estabelecer convênios com instituições como a Fundação Francisca Trindade, Serviço Social do Comércio- SESC, Sucesso em Desenvolvimento Comercial e Eventos- SENADE, Sindicato dos Trabalhadores em Telefonia- SINTEL, para a realização de cursos profissionalizantes que beneficiem as usuárias.

A articulação dos serviços do Centro com a rede de atendimento é confirmada por algumas funcionárias, afirmando que existem atendimentos que necessitam de encaminhados a outras instituições como a DEAM Zona Norte, Defensoria Pública, Núcleo de Defesa da Mulher, Centro de Assistência Psicossocial- CAPS, Centro de Referência a Assistência Social- CRAS, Serviço de Atenção à Mulher Vítima de Violência Sexual- SANVIS e Centro de Referência Especializado de Assistência Social- CREAS.

No entanto, há divergências de opinião entre funcionários a respeito da articulação do Centro com as instituições da rede de atendimento, como pode ser visto a seguir: "há comunicação com as instituições da rede, as meninas já foram a outros órgãos para se apresentar, além de escolas e posto de saúde, para falar sobre o trabalho do Centro" (C.R 26/10/11 9:50h); "a rede de atendimento não esta funcionando, mas no começo funcionava" (C.R 07/11/11 12:05h).

No que se refere ao acompanhamento ou atendimento continuado dos casos atendidos, parece ser parcial como pode se observar na colocação por parte desse funcionário: "Nós não acompanhamos os casos até o final, só acompanhamos até a defensoria (C.R 04/11/11 11:20h).

Observou-se que quando é necessário são feitas visitas domiciliares para averiguar a situação das usuárias. Em casos de tratamento psicológico o contato da usuária com o C.R costuma ser mais longo, mas com a falta d profissional especializado não está ocorrendo no momento. Entretanto, o acompanhamento é uma fase importante na intervenção do ciclo de violência, pois como diz Velásquez (2006), ao sentir-se cuidada e acompanhada a mulher tem a possibilidade de unir imagens, associar palavras, sensações e memórias, o que lhe ajuda a se posicionar como um sujeito ativo na situação de violência, reagindo a esta.

A procura das mulheres ao atendimento jurídico, que se resume a orientações sobre seus direitos também está reduzida na atualidade. No período da pesquisa de campo só 3 (três) mulheres em situação de violência compareceram ao Centro, uma no dia 21/10/11 e duas no dia 04/11/11. A usuária do dia 21/10/11 havia sofrido uma agressão e ligou para o Centro, a funcionária ao atender ao telefone recomendou que a vítima viesse a DEAM para registrar um boletim de ocorrência e que depois fosse ao Centro. A mulher estava resistente, pois não tinha dinheiro para pagar o ônibus, mas a funcionária lhe informou que o Centro disponibiliza de vales transporte às usuárias.

A usuária chegou por volta das 11:30h, passou pela recepção aonde preencheu a ficha de cadastro, só lhe foram feitas perguntas referentes a dados pessoais, o que levou em torno de dez minutos. Na sequência, essa passou para sala da assistente social, aonde recebeu orientações jurídicas, pois queria a separação judicial. $\mathrm{O}$ atendimento constituiu em informar quais os seus direitos, os documentos necessários para dar entrada ao processo de divórcio e pedido da guarda dos filhos, sendo assim, ela foram encaminhados à defensoria pública.

As mulheres que compareceram no dia 04/11/11 não eram vítimas de violência (ao menos foi assim que se declararam), só queriam orientação jurídica para questões de divórcio e divisão de bens, essas também foram encaminhadas a defensoria pública. Há uma comunicação frequente com a Defensoria pública, como ser visto no seguinte comentário: "a defensoria é uma grande parceira, ela nos ajuda muito" (C.R 04/11/11 10:00h).

De acordo com funcionários do Centro do período de sua inauguração, em 2007 até o final de 2009, este funcionava muito bem, apresentando uma média de oito atendimentos por dia. Nos últimos dois anos essa média vem caindo e no período da referida pesquisa presenciou-se apenas três atendimentos. Percebeu-se que os funcionários, em geral, ficam ociosos e, por consequência, desanimados e desestimulados com o trabalho, visto que se sentem inseguros, não satisfeitos com as acomodações e local de funcionamento do trabalho, além de perceberem pouca visibilidade e valorização do seu trabalho junto a Rede de Atendimento no combate e enfrentamento da violência de gênero.

O trabalho do Centro de Referência Francisca Trindade deveria ser visto e valorizado como de grande relevância, visto que o objetivo dessa instituição é auxiliar de forma multidisciplinar a mulher em situação de violência, como sugere Silveira (2005), consiste em intervir no ciclo de violência, ajudando a mulher a romper com o mesmo, recuperando a história de violência para que possa se posicionar como sujeito, reagindo a essa situação.

Os serviços oferecidos pelas instituições que compõem a rede de atendimento têm uma característica importante, como alude Strey, Nora e Werba (2004), uma vez que possibilita a legitimação de ações violentas contra mulheres como crimes. 
Quando o atendimento é bem qualificado a mulher é acolhida e tranquilizada conseguindo, assim, decidir melhor o que fazer naquela situação. Por isso, um atendimento prestado por uma equipe especializada, sobretudo, capacitada em gênero é indispensável, pois como aponta Velásquez (2006), a violência de gênero é ampla e multifacetada e para abordá-la de forma adequada uma equipe de trabalho deve estar informado, assim como problematizar os aspectos sociais e culturais da construção de gênero, que se dá através dos processos de socialização nas principais instituições sociais como escola, estado, família e igrejas.

No entanto, as precárias condições físicoestruturais do funcionamento, a falta de profissionais especializados, a falta de incentivo, frequência de capacitação na área de gênero, baixos salários, precárias condições de trabalho, de segurança e privacidade a funcionários e usuários são fatores que acabam instituindo um atendimento não adequado, como se pode perceber no caso do Centro de Referência, em discussão.

Faz-se, assim, necessários maiores investimentos e atenção por parte do poder público na área de segurança (nacional e local) e mais especificamente a Secretaria Nacional de Políticas Públicas para as Mulheres, Secretária de Assistência Social e Cidadania - SASC, Diretoria da Unidade de Políticas Públicas para Mulheres - DUPM efetivarem um trabalho articulado e integrado, como reza as Normas de Padronização do Atendimento em relação às instituições que compõem a Rede de Atendimento, pois são elementos fundamentais no combate $\mathrm{e}$ enfrentamento a violência. É preciso que, em geral, cada uma dessas instituições da Rede de Atendimento, no país, esteja funcionando de forma adequada tanto, no que se refere as condições físico-estruturais do atendimento, como em relação à formação e capacitação profissional que, além disso, também precisam de boas condições de trabalho e de bons salários para desempenharem o seu ofício com dignidade e satisfação.

\section{Considerações Finais}

A perseverança das desigualdades e hierarquias de gênero e, consequentemente, as práticas de violência contra a mulher são reflexos de uma sociedade patriarcal e machista. O uso de práticas violentas de gênero ainda é, de certa forma, naturalizada e aceita em determinadas situações pela sociedade e pelas próprias vítimas, o que dificulta a visibilidade e o combate efetivo a esse tipo de violência. Dessa forma, as criações de mecanismos intervencionistas que deem visibilidade previnam e combatam esse tipo de violência é essencial a transformação desse quadro presente em espaços públicos e privados.

Os Centros de Referência, instituições da rede de atendimento aqui discutidas são resultado das reivindicações dos movimentos sociais e feministas e se constituem como núcleo de assistência multiprofissional, objetivando intervir no ciclo da violência, utilizando a escuta integral de forma unificada. $\mathrm{O}$ atendimento tem como base $\mathrm{o}$ acolhimento, monitoramento e acompanhamento permanente das usuárias atendidas, por isso as práticas dos profissionais e os procedimentos de atendimento devem tomar como base o questionamento e a desconstrução das relações de dominação e opressão entre os gêneros.

Os resultados dessa pesquisa constataram através das observações feitas, que as condições físicoestruturais e o atendimento, propriamente dito, deixam a desejar no sentido de constituir um atendimento adequado, conforme orientações das Normas de Padronização do Atendimento (2006) a exemplo dos problemas estruturais do local de atendimento faltam de adaptações para portadores de necessidades especiais, falta de segurança, difícil acessibilidade, poucos funcionários e falta da presença de corpo funcional especializado em determinadas áreas, além de profissionais em relação ao trabalho.

$\mathrm{O}$ atendimento apresenta sérias dificuldades, estando quase inexistente no momento, e atendendo a um número cada vez menor de mulheres, em parte devido à falta de profissionais e de uma comunicação mais eficaz em termos de articulação e integração com as demais intuições da rede de atendimento.

A articulação com a rede se encontra mais em nível jurídico, ocorrendo de forma mais sistemática com a defensoria pública. Observou-se também que o acompanhamento continuado dos casos atendidos não acontece de forma corriqueira e nem percorre todo o processo de atendimento, limita-se aos casos mais extremos.

Diante do exposto, sugere-se por parte da segurança pública, a atenção devida e urgente a essa instituição, em particular, devido a sua relevância no combate e enfrentamento da violência contra a mulher, valorizando, incentivando, capacitando e fornecendo condições estruturais e qualificação profissional adequada para que o mesmo possa realizar seus trabalhos de forma eficiente e eficaz e, consequentemente, poder contribuir, de fato, para conter esse grave problema social da violência doméstica e familiar em nosso país.

Sendo assim, sugerem-se medidas urgentes a serem implantadas em relação ao Centro de Referência, como 
a transferência do local aonde atualmente funciona, para um local mais centralizado e com melhor acessibilidade, possibilitando uma divulgação mais ampla dos serviços dessa instituição e beneficiando, assim, um maior número de mulheres.

Faz-se necessário também a contratação de funcionários efetivos para a equipe técnica de profissionais, favorecendo certa estabilidade e fixidez de um quadro profissional na instituição, possibilitando maior interação e confiança para a realização de atividades mais estruturais e duradouras. Faz-se necessário e importante as capacitações continuadas na área de gênero ao corpo profissional para que se constitua como corpo especializado na questão a que atendem, gênero. Assim como incentiválos no quadro de cargos e salários, a cursar pósgraduação em nível de mestrado e doutorado. Nestes sentidos, aqui expostos, sugiro parcerias com a Universidade Federal do Piauí que além de pósgraduação na área mencionada, ainda conta com um corpo de especialista nas gestões de gênero e família.

Bem como a ampliação e concretização de um canal de comunicação efetivo entre as instituições da rede de atendimento antiviolência, em especial com as Delegacias Especializadas de Atendimento a Mulher, importante no sentido de gerar um atendimento contínuo às usuárias, diminuindo dessa forma a reincidência ou permanência da mesma mulher na situação de violência sofrida.

1 O SOS mulher surgiu nos anos 70, como a primeira experiência brasileira de contato direto com as mulheres vítimas de violência. Este possuía referencial feminista e tinha como proposta fundamental a recusa ao assistencialismo, trabalhando com a conscientização das mulheres a respeito das questões feministas.

2 Esse nome foi escolhido para homenagear a cantora Eliane Grammont, que foi assassinada pelo exmarido após terminar a relação, em março de 1981. Esse caso teve grande repercussão, causando uma grande mobilização nos movimentos de mulheres antiviolência.

3 São espaços de convivência em que as mulheres trocam experiências de violências vividas com o intuito de fortalecer vínculos interpessoais.

$4 \quad$ É uma técnica que permite ao pesquisador tornar-se parte do lócus de pesquisa, o que possibilita uma compreensão aprofundada significações presentes nas ações e praticas produzidas pelos sujeitos (MAY, 2004).

5 Devido ao fato do Centro de Referencia ser uma instituição pública gerenciado pela Diretoria da Unidade de Políticas para Mulheres- DUPM e vinculado a Secretária de Assistencial Social e Cidadania- SASC foi necessário receber uma autorização deste órgão para que a pesquisa fosse aplicada.

6 Consiste na construção de uma ficha social em que é registrado o histórico de violência da usuária, e partir das informações se determina o tipo de atendimento necessário e os encaminhamentos a serem feitos. Essas informações também são utilizadas para futuras pesquisas a serem realizadas pelo Centro ou Secretaria de Políticas para Mulheres.

\section{Referências}

ALVES, Sandra Lúcia Belo, DINIZ Maria Freire Diniz. 'Eu digo não, ela diz sim': A violência conjugal no discurso masculino. Revista Brasileira de Enfermagem, v. 58, n. 4, p. 387 - 392, 2005.

BOURDIEU, Pierre. A Dominação Masculina. Rio de Janeiro: Bertrand Brasil, 2002.

ARAÚJO, Islene Cristina Cardoso de; MELO, Raimunda Pinheiro B. Violência contra a mulher em Teresina/PI: apresentação de resultados de atendimento no centro de referência para mulheres vítimas de violência Francisca Trindade. Secretaria de Assistência Social e Cidadania, Diretoria de Políticas para Mulheres. Teresina, 2009.

CÔRTEZ, Gisele Rocha. Violência doméstica contra mulheres: Centro de referência a mulher Araraquara. Universidade Estadual Paulista. Faculdade de Ciências e Letras, São Paulo, 2008.

GOLDEMBERG, Mirian. A arte de Pesquisar: como fazer pesquisa qualitativa em Ciências Sociais. Rio de Janeiro: Record, 2007.

MORAES, Aparecida Fonseca; GOMES, Carla de Castro. $\mathrm{O}$ caleidoscópio da violência conjugal: instituições, atores e políticas públicas no Rio de Janeiro. In: MORAES, Aparecida Fonseca \& SORJ, Bila (orgs). Gênero, violência e direitos na sociedade brasileira. Rio de Janeiro: 7 Letras, 2009, p. 75 - 109. PRESIDÊNCIA DA REPÚBLICA, Casa Civil, 
Atendimento às Mulheres em Situação de

Violência no Centro de Referência Francisca

Trindade, em Teresina - PI

Subchefia para Assuntos Jurídicos. Lei $\mathbf{n}^{\mathbf{0}}$ 11.340, de 07 de agosto de 2006. Brasília, 2006.

PRESIDÊNCIA DA REPÚBLICA; SECRETARIA DE POLÍTICAS PÚBLICAS PARA MULHERES. Norma técnica de uniformização dos Centros de Referência Atendimento a mulher em situação de violência. Brasília, 2006.

SAFFIOTI, Heleiet I.B, Já se mete a colher em briga de marido e mulher. São Paulo em Perspectiva. v. 13, n.4, p. 82 - 91, 1999.

\section{SECRETARIA DE POLÍTICAS PÚBLICAS PARA MULHERES; PRESIDÊNCIA DA REPÚBLICA; MINISTÉRIO DA JUSTIÇA; UNODOC- ESCRITÓRIO DAS NAÇÕES UNIDAS. Norma técnica de padronização das delegacias especializadas de atendimento a mulheres- DEAMS. Brasília, 2010.}

SECRETARIA DE POLÍTICAS PÚBLICAS PARA MULHERES. Rede de enfrentamento a violência à violência contra mulheres e atendimento a mulher em situação de violência. Brasília, 2010.

SECRETARIA DE POLÍTICAS PÚBLICAS PARA MULHERES; PRESIDÊNCIA DA REPÚBLICA. Pacto nacional pelo enfrentamento a violência contra mulher. Brasília, 2007.

SILVEIRA, Lenira Politano da. Serviços de atendimento a mulheres vítimas de violência. Rio de Janeiro: Advocacia Cidadã pelos Direitos Humanos, 2005.

SCOTT, Joan. Gênero uma categoria útil para análise histórica. Recife: SOS/CORPO, 1989.

STREY, Marlene Neves; WERBA, Graziela C.; NORA, Thais Cardoso. 'Outra vez essa mulher?' Processo de atendimento a mulheres em situação de violência nas delegacias da mulher do RS. In: STREY, Marlene Neves; AZAMBUJA, Mariana P. Ruwer de; JAEGER, Fernanda Pires (orgs.). Violência, Gênero e Políticas Públicas. Porto Alegre: EDIPUCRS, 2004, p. $101-122$.

VELÁSQUEZ, Susana. Violências cotidianas,violência de gênero: escuchar, compreender, ayudar. Buenos Aires: Paidós, 2006. 